\title{
Congenital fistulae of the lacrimal gland
}

\author{
LIEUWE J. BLANKSMA AND BERT A. E. V.D. POL \\ From the University Eye Clinic, Groningen, The Netherlands
}

SUMMARY A 36-year-old man had congenital fistulae of the palpebral lobes of the lacrimal glands, with orifices bilaterally in the intermarginal strip of his upper eyelids near the external canthi. The left fistula was cystic and had become chronically inflamed. Because antibiotic therapy was unsuccessful, excision was necessary. Congenital fistulae are extremely rare, forming a lateral and tarsal group, each group having typical characteristics.

Congenital fistulae of the lacrimal gland are rare. We could find only 13 reports in the literature, usually affecting children. None of these descriptions reports a bilateral occurrence.

\section{Case report}

A 36-year-old man complained for a year of discharge of purulent material from the external canthus of his left eye, especially when he exerted pressure on the temporal part of his upper eyelid. Local therapy with antibiotics had failed. He had

Correspondence to Dr L. J. Blanksma, Department of Ophthalmology, University Hospital, 59 Oostersingel, 9713 EZ Groningen, The Netherlands. no other complaints and was in a good health. Both eyes were normal.

In the intermarginal strip of both upper eyelids, just against the external canthus, a fistula could be seen with an orifice the size of a pin head. The conjunctiva of the left eye was hyperaemic, and a small yellow purulent discharge came from the fistula. The right eye was symptomless and normal lacrimal fluid exuded from the fistula. Apart from these 2 small openings the eyelids of both eyes were quite normal.

The purulent material from the left fistula proved to be sterile. With a probe $0.5 \mathrm{~mm}$ diameter the left fistula was traceable for $18 \mathrm{~mm}$ (Fig. 1) and the right for $4 \mathrm{~mm}$. The lacrimal passages on both sides were normal.

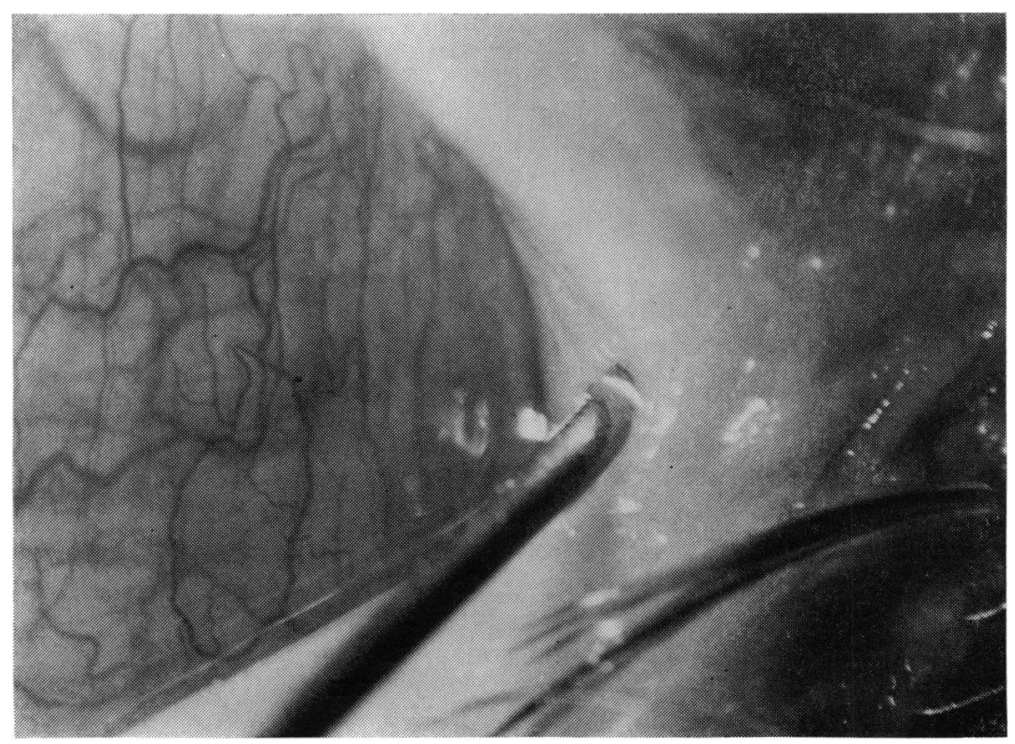

Fig. 1 Probe in the lacrimal gland fistula of the left eye. 
Fig. 2 X-ray contrast photography demonstrating the cystic enlargement of the left fistula and the 2 diverticulae of the right fistula.
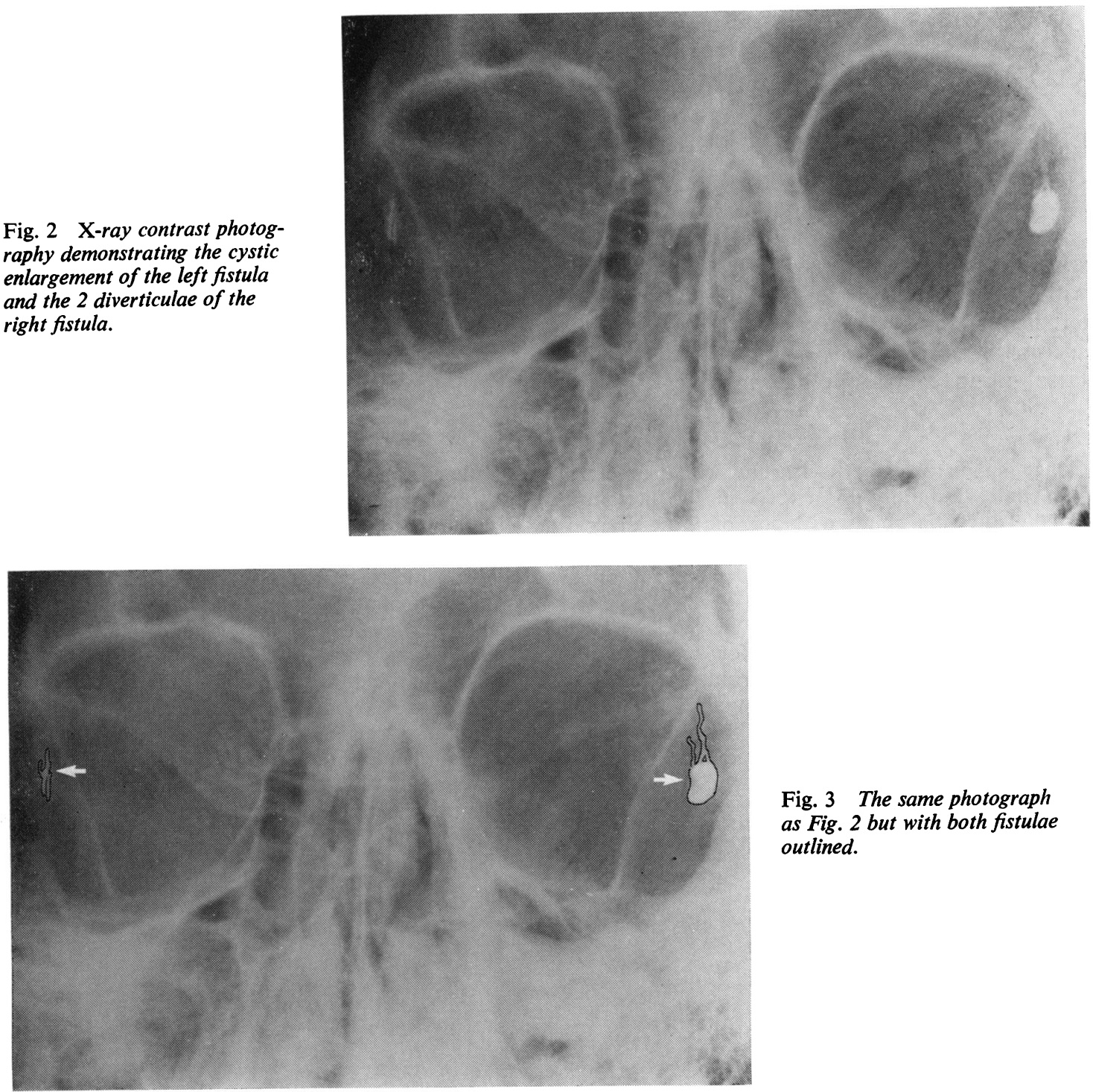

Fig. 3 The same photograph as Fig. 2 but with both fistulae outlined.

$X$-ray contrast photography showed the fistula on the left to be cystic just above the cutaneous orifice (Figs. 2 and 3). Cranially to this cyst 2 small ducts ran up in the direction of the palpebral part of the lacrimal gland. On the right side the fistula was straight and had 2 diverticulae.

As conservative therapy had failed, we decided to operate on the left fistula. Under general anaesthesia a probe $0.5 \mathrm{~mm}$ in diameter was pushed up to the palpebral part of the lacrimal gland. After turning the upper eyelid this probe was well seen just beneath the conjunctiva. With the probe as guide the conjunctiva was incised and the fistula was totally extirpated together with some neighbouring tissue of the palpebral part of the lacrimal gland. The conjunctiva was then closed with 8-0 virgin silk.

The postoperative course was uneventful. After a follow-up of 1 year no recurrences or cysts were present in the operative field and the patient was symptom free.

On microscopic examination the wall of the fistula appeared to be composed of multilayered nonkeratising squamous epithelium surrounded by connective tissue, with some polymorph nucleated inflammatory infiltrates. 


\section{Discussion}

Lacrimal fistulae can be divided into 2 groups according to the situation and the anatomy of their orifice in the eyelid (Fig. 4).

(1) The tarsal group has the orifice near the upper rim of the tarsal plate of the upper eyelid, either in the centre or near the temporal canthus. In all the cases described a tuft of hair was found around the orifice. ${ }^{1-4}$

(2) The lateral group has the orifice at some distance ( 3 to $35 \mathrm{~mm}$ ) from the external canthus. A tuft of hair is never found around the orifice..$^{5-13}$ With the exception of 1 case $^{6}$ the eyelids have a normal anatomy.

Both fistulae of our patient were in the lateral group. The $x$-ray examination confirmed that both

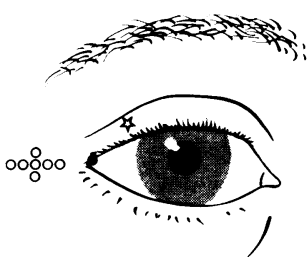

OD

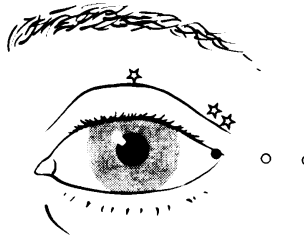

OS
Fig. 4 All cases of congenital lacrimal gland fistulae found in the literature, together with our own case. is Tarsal group with the orifice near the upper rim of the tarsal plate and with a tuft of hair. $\bigcirc$ Lateral group with the orifice near the external canthus and never with a tuft of hair. Both fistulae of our own patient.

drained from the palpebral part of the lacrimal gland. Whether the cystic enlargement on the left side is the cause or the result of the inflammation remains an open question. But it is obvious that the small diverticulae of the right fistula ran the risk of becoming inflamed as well. The $x$-ray descriptions of Schornstein, ${ }^{4}$ Frey, ${ }^{7}$ Damato,${ }^{8}$ and Carpenter and Annamunthodo ${ }^{10}$ are similar to our findings.

Terlinck, ${ }^{2}$ Malhotra, ${ }^{9}$ and Carpenter and Annamunthodo ${ }^{10}$ state that the fistula should be transplanted into the upper conjunctival cul-de-sac, and they report moderate success for their opera- tions. In contrast Ling, ${ }^{6}$ Schornstein, ${ }^{4}$ and Frey ${ }^{7}$ excised the fistulae together with the adherent piece of the lacrimal gland. This method was followed by us. The excretory ducts of the orbital part of the lacrimal gland run through the palpebral part before they end in the conjunctival fornix. Thus with the excision of a congenital lacrimal fistula one should take away only that part of the palpebral lobe of the lacrimal gland that drains into this fistula and certainly not more.

The epithelial lining of the excised fistula has been described in 3 cases. Ling ${ }^{6}$ and Schornstein ${ }^{4}$ found stratified squamous epithelium, but Terlinck ${ }^{2}$ compared the wall of the fistula with cutaneous tissue and even described hair follicles and sweat glands. In our case we met with multilayered nonkeratising squamous epithelium with a chronically inflamed infiltrate underneath. The piece of palpebral lacrimal gland was structurally normal.

The majority of the cases described were in children, who have no complaints, but their parents were anxious. Our patient had lived for many years unaware of his 2 fistulae, until 1 of them became infected.

\section{References}

${ }^{1}$ Steinheim. Fistula lacrymalis vera congenita. Klin Monatsbl Augenheilkd 1875; 13: 303-5.

${ }^{2}$ Terlinck H. Ein Fall von angeborener Fistel der Tränendrüse. Z Augenheilkd 1910; 24: 522-3.

${ }^{3}$ Gallemaerts E. Fistule palpébrale de la glande lacrymale accessoire. Ann Oculistique 1919; 156: 127-8.

'Schornstein T. Zur Frage der angeborenen Tränendrüsenfistel. Arch Augenheilkd 1936; 109: 86-102.

${ }^{5}$ Moritz. Abnormer Ausmundung einer Thränendrüse. Munch Med Wochenschr 1898; 45: 948.

${ }^{6}$ Ling WP. Anomalous duct of the lacrimal gland associated with other congenital anomalies. Am J Ophthalmol 1926; 9: $\mathbf{1 - 2 .}$.

${ }^{7}$ Frey G. Congenital fistula of the lacrimal gland. Arch Ophthalmol 1938; 20: 685 .

${ }^{8}$ Damato FJ. Congenital fistula of the lacrimal gland. Br J Ophthalmol 1956; 40: 506-8.

${ }^{9}$ Malhotra M. Congenital fistula of lacrimal duct. $B r J$ Ophthalmol 1956; 40: 559-61.

${ }^{10}$ Carpenter R, Annamunthodo H. Anomalous lacrimal ductule. Br J Ophthalmol 1966; 50: 159-61.

${ }^{11}$ Desai HG. Congenital fistula of the lacrimal gland. $\mathrm{Br} \mathrm{J}$ Ophthalmol 1967; 51 : 206-7.

${ }^{12}$ Diallo J. Fistule congénitale externe de la glande lacrymale. Bull Soc Med Afr Noire Lang Fr 1968; 13: 391-2.

${ }^{13}$ Shapiro I, Gorlin RJ. Congenital fistula of the lacrimal gland. J Pediatr Ophthalmol 1969; 6: 25-7. 